\title{
A fenomenologia como método aplicado à ciência de enfermagem: estudo de investigação
}

\author{
Phenomenology as a method applied to nursing science: \\ research study
}

Carolina Miguel da Graça Henriques (https://orcid.org/0000-0002-0904-8057) ${ }^{1}$

Maria Antónia Rebelo Botelho (https://orcid.org/0000-0001-7356-2053) ${ }^{2}$

Helena da Conceição Pereira Catarino (https://orcid.org/0000-0002-8617-7629) ${ }^{1}$

${ }^{1}$ Escola Superior de Saúde, Center for Innovative Care and Health Technology (ciTechCare), Instituto, Politécnico de Leiria. R. Gen. Norton de Matos Apartado 4133. 2411-901 Leiria Portugal. carolina. henriques@ ipleiria.pt

${ }^{2}$ Escola Superior de Enfermagem de Lisboa. Lisboa Portugal.

\begin{abstract}
In a more inductive or deductive way, several theorists have problematized about nursing care in which they seek to clarify nursing science focus of attention. The phenomenological perspective allows us to perceive the human lived experience and unveil their meaningful understanding as a person. Stemming from the question 'What is the lived transition experience of the maternal role of women with problems of addiction to psychoactive substances, from pregnancy to the first year of the child's life?' This research distills the core principles of a qualitative research, with a phenomenological and interpretative design, with the objective of understanding the lived experience transition process of the maternal role of women with problems psychoactive substances addition. The research does not only reveal the contribution of phenomenological studies in the development of nursing science, but also enhances the living experience of women with addiction problems to psychoactive substances, during pregnancy, childbirth, postpartum and the first year of their children's life, enabling nurses to develop specific interventions to dealt with this problematic issue under study.
\end{abstract}

Key words Phenomenology, Living experience, Nursing, Maternal role
Resumo De uma forma mais indutiva ou dedutiva, diversos teóricos têm problematizado sobre o cuidar em enfermagem em que procuram clarificar o foco de atenção da Ciência de Enfermagem. A Perspetiva Fenomenológica permite-nos o entendimento do Homem e possibilita a desocultação do vivido. Partindo da questão 'qual é a experiência vivida da transição para o papel maternal de mulheres com problemas de adição a substâncias psicoativas, desde a gravidez ao primeiro ano de vida do filho?' entraremos num estudo de natureza qualitativa, de desenho fenomenológico $e$ interpretativo, com o objetivo de compreender a experiência vivida da transição para o papel maternal de mulheres com problemas de adição a substâncias psicoativas. A pesquisa não só faz emergir o contributo dos estudos fenomenológicos para o desenvolvimento da Ciência de Enfermagem como se debruça sobre a experiência vivida de mulheres com problemas de adição a substâncias psicoativas, em que são evidenciados os momentos vividos por estas mulheres na gravidez, parto, pós-parto e primeiro ano de vida dos filhos, possibilitando aos enfermeiros o desenvolvimento de intervenções de enfermagem específicas face à problemática em estudo.

Palavras-chave Fenomenologia, Experiência vivida, Enfermagem, Papel maternal 


\section{Introdução}

Sabendo que a pessoa é um individuo humano em relação com o mundo e em desenvolvimento permanente através das escolhas que realiza e da interação com os outros ${ }^{1}$, a enfermagem é uma resposta nutridora intencionalmente dirigida ao bem-estar da pessoa, ajudando-a a tornar-se tanto mais humana quanto possível, na sua situação particular ${ }^{1}$. Por outro, o cuidar em enfermagem é uma experiência vivida entre humanos, numa relação intersubjetiva na qual o processo de nutrir ocorre, envolvendo um modo de ser e de fazer com o outro, situado num determinado tempo e espaço.

Ser-se enfermeiro é dar e construir significados das experiências vividas, permitindo realizar um 'cuidado' de enfermagem significativo ao outro. Que entendimento conceptual tem a Enfermagem e os Enfermeiros da experiência vivida, o seu significado do ponto de vista daqueles que a vivem? Na resposta a estas duas questões, os enfermeiros têm desenvolvido estudos de cariz fenomenológico que têm alicerçado a construção de teorias de grande e médio alcance que suportam as práticas profissionais em enfermagem. Não obstante, não podemos esquecer-nos de alertar que a aplicação do método fenomenológico para a disciplina da Enfermagem, "centrada sobretudo no campo da experiência vivida, tal como vivida, deve ser feita com a utilização de estratégias de rigor adequadas e devidamente enquadradas no processo de investigação, e isso implica um conhecimento do método e da sua linguagem"2, principalmente no que diz respeito aos referenciais onto-epistemológicos.

Mas quem é este Outro que interpela o Enfermeiro na sua ação do Cuidar?

Para Heidegger ${ }^{3}$, só o homem (ser-aí) existe, sendo este privilegiado, devido "a aceitação do dom da existência que lhe entrega a responsabilidade e a tarefa de ser e assumir esse dom", uma vez que o homem só pode ser "compreendido a partir da sua existência, da possibilidade (que the é própria) de ser ou não ser ele mesmo".

Configurando-se a situação do homem como clareira do ser, onde este se esconde e se revela, Dasein, é marcado pela pre-sença, a qual, só é possível com fundamento no ser-no-mundo em geral $^{3}$. A compreensão do ser-no-mundo como estrutura essencial da presença é que possibilita a "visão penetrante da espacialidade existencial da pre-sença". Dasein, este ser-no-mundo, é alguém que "espacializa", por ser pre-sença no mundo no qual se encontra. Para além destas características, o homem (Dasein) é um ser-no-mundo e um ser-com-o-outro, com consciência do eu, afirmação de si mesmo e da própria identidade, que interage com outros seres e se relaciona com estes, “[...] o ser simplesmente dado é o modo de ser de um ente que não possui o carácter de presença".

Desta forma, a vida oferece ao Homem a experiência, em que através da sua compreensão, este se autoapreende, regressa e se encontra a si mesmo. A experiência vivida é tida como objeto de estudo, em que o conjunto complexo de dados num todo indivisível, cria um corpo de conhecimentos profundamente compreensivo e interpretativo. A experiência humana, assente numa história e numa cultura, perfaz a relação deste consigo próprio e com o mundo, em que a realidade pré-refletida faz com que o Homem tome consciência de si situadamente ${ }^{4}$.

Em Heidegger, o ato de desocultação, a abertura entre Dasein (ser aí) e os objetos que preenchem o mundo, desempenha a função da razão, portadora do real. A verdade está no combate entre a clareira e a ocultação, em que o próprio ser, a partir da sua essência, faz acontecer ${ }^{5}$. Sob um eixo interpretativo, os fenómenos são estudados nas situações vividas pelas pessoas, enfatizando a compreensão do significado que os indivíduos atribuem às suas ações, indo ao encontro da premissa da prestação de cuidados de enfermagem individualizados, assente numa filosofia de compromisso moral para com o outro ${ }^{6}$.

Assim, o cuidar é o cerne da enfermagem, exigindo o desenvolvimento de conhecimento científico próprio, em que os estudos fenomenológicos poderão contribuir, construir e aprofundar quadros de referência, articulando conceitos, valores e crenças que correspondem à concepção de cuidar em enfermagem. Através da questão 'Qual é Experiência Vivida da Transição para o Papel Maternal de Mulheres com Problemas de Adição a Substâncias Psicoativas, desde a gravidez ao primeiro ano de vida do filho?' e com o objetivo de compreender a experiência vivida da transição para o papel maternal de mulheres com problemas de adição a substâncias psicoativas, desde a gravidez ao primeiro ano de vida do filho, propusemo-nos desenvolver um estudo fenomenológico que pudesse contribuir para fortalecer o mapeamento conceptual da problemática em estudo, tal como para sustentar melhores práticas de enfermagem a Mulheres Mães com Problemas de Adição a Substâncias Psicoativas. 


\section{A interação do enfermeiro com o ser vivido}

Segundo Meleis ${ }^{7}$, o enfermeiro interage com o Outro (cliente de enfermagem), numa situação de saúde-doença em que o Ser Humano é parte integrante do seu ambiente e que está a viver uma transição. Estas interações entre o enfermeiro e o seu cliente (o Outro) organizam-se em torno de uma intenção (processo de enfermagem) e o enfermeiro utiliza intervenções (terapêuticas de enfermagem) para promover, recuperar ou facilitar a saúde. Partindo deste entendimento, os seres humanos são como sujeitos vivenciados nos processos de saúde-doença e os enfermeiros, os profissionais que acompanham as situações experienciadas (nos processos de saúde e doença), tal como na elaboração e significação posterior e na exploração cuidativa do sentido do vivido para quem o viveu"s.

Se o ser humano só pode ser compreendido a partir da sua própria existência, a experiência vivida das mulheres aquando da gravidez, parto, pós-parto e primeiros anos de vida da criança, possibilita a exploração do vivido por estas e permite o conhecimento por parte dos enfermeiros dos processos de ajustamento e de transição ao papel maternal para que posteriormente possam conceber processos cuidativos significativos para as mesmas.

Continuando a assistir-se a uma conceção naturalista e essencialista do processo de 'tornarse e ser-se mãe' , percepcionamos a necessidade de desocultar a experiência vivida de mulheres com problemas de adição a substâncias psicoativas face à transição para o papel maternal, considerando-as como seres experienciados, em que a enfermagem poderá contribuir para a compreensão do fenómeno, ocupando-se assim da resposta humana aos processos de vida 9 .

\section{Método}

Trata-se de um estudo fenomenológico, transversal e retrospetivo, de cariz interpretativo assente na fenomenologia existencial de Heidegger $^{3,5}$ e na hermenêutica de Gadamer ${ }^{10-12}$.

Considerando de que fenomenologia é tendencialmente descritiva e interpretativa, linguística e hermenêutica ${ }^{9}$, esta constitui-se uma via de acesso ao mundo como nós o experienciamos pré-refletidamente ${ }^{13}$. Para Gadamer ${ }^{11}$, o Homem situado num tempo, num espaço e numa cultura que faz com que este esteja imerso por preconceitos transmitidos ou construídos durante a sua vida, por outro, cada intérprete está imerso num conjunto de pré-juízos que fazem parte do seu ser.

$\mathrm{O}$ ato interpretativo é um encontrar-se, que se dá na abertura à alteridade da coisa que se busca compreender ${ }^{11}$. É no momento fusional do encontro com o outro, que se ancora o processo dialógico de compreensão, processo este mutável e dinâmico.

O círculo hermenêutico de interpretação desloca-se de frente e para trás, com início no presente. $\mathrm{O}$ processo interpretativo subjacente ao significado surge das interações, trabalhando para fora e para trás, de si para o acontecimento e do acontecimento para si. A investigação fenomenológica aplicada à enfermagem permite-nos responder a questões de como a experiência dos seres humanos é vivida e como dá sentido à vida humana, possibilitando-nos compreender como se constrói a realidade tal como é experienciada pelos sujeitos ${ }^{13}$.

Atendendo à nossa questão de investigação e procurando a compreensão da experiência vivida da transição para o papel maternal de mulheres com problemas de adição a substâncias psicoativas, desde a gravidez ao primeiro ano de vida do filho, partimos para encontros significativos com estas mulheres, através de uma amostragem com propósito. A seleção foi orientada com a ajuda das equipas de enfermagem de três Equipas Técnicas Especializadas de Tratamento da Região Centro de Portugal (Serviço de Intervenção nos Comportamentos Aditivos e nas Dependências, Sicad). Como critérios de elegibilidade para a participação no nosso estudo definimos: mães com idades compreendidas entre os 18 e os 35 anos, que soubessem ler e escrever e que acordassem voluntariamente participar na investigação. Todas as participantes estavam ao abrigo de programas terapêuticos (substituição narcótica de opiáceos) no âmbito dos Centros de Respostas Integradas, desde o período pré-natal até ao momento da colheita de dados. Participaram no estudo catorze mulheres (Quadro 1).

Foi utilizada a entrevista fenomenológica com uma abordagem não estruturada para a colheita dos dados, procurando que as participantes narrassem a sua experiência vivida do fenómeno.

O estudo foi autorizado pela Administração Regional do Centro - Portugal, e pelo Serviço de Intervenção nos Comportamentos Aditivos e nas Dependências. Foi aprovado pela respetiva Comissão de Ética da Administração Regional do Centro, Portugal.

Realizadas as entrevistas, o investigador procedeu à sua transcrição, associando as notas de 


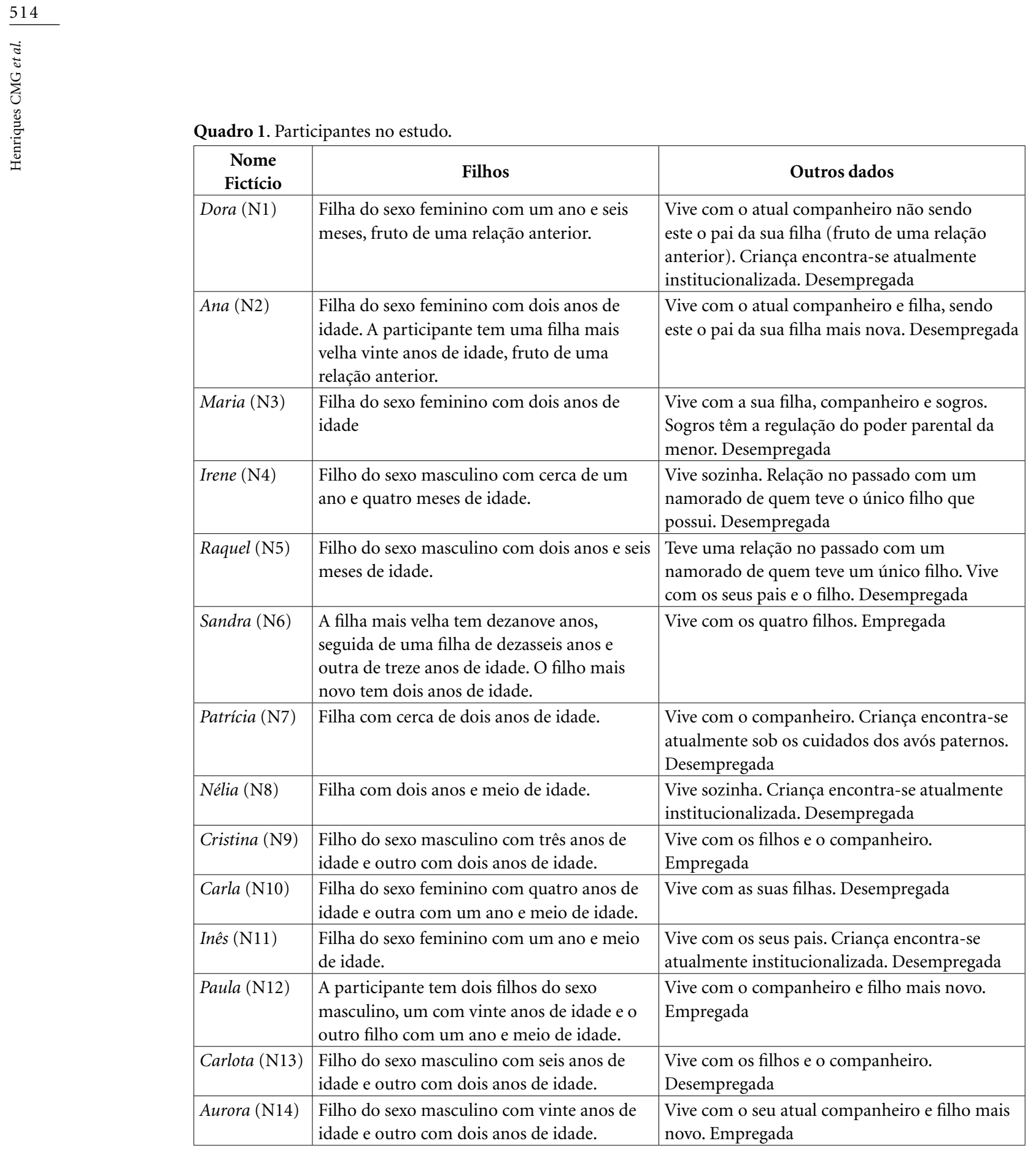

campo tomadas no decurso das mesmas. Foram, ainda, realizados genogramas simples tendo por base as informações fornecidas pelas participantes (Figura 1).

Posteriormente à transcrição completa, o texto narrativo foi enviado às participantes com o objetivo de estas validarem o processo de transcrição realizado pela investigadora. Para rigor metodológico, nenhuma entrevista foi realizada sem que a anterior tivesse sido transcrita. Este aspeto é de especial relevância em estudos fe- nomenológicos, em que se pretende a procura da compreensão de determinado fenómeno e o desvelar das experiências vividas dos sujeitos9. "A linguagem é o médium universal em que se realiza a própria compreensão. A forma de realização da compreensão é a interpretação" ${ }^{11}$.

Tendo as participantes corroborado com processo de transcrição das entrevistas, os textos foram reanalisados e foram retirados os aspetos narrativos referenciados pelas participantes não relacionados com o fenómeno em estudo, per- 


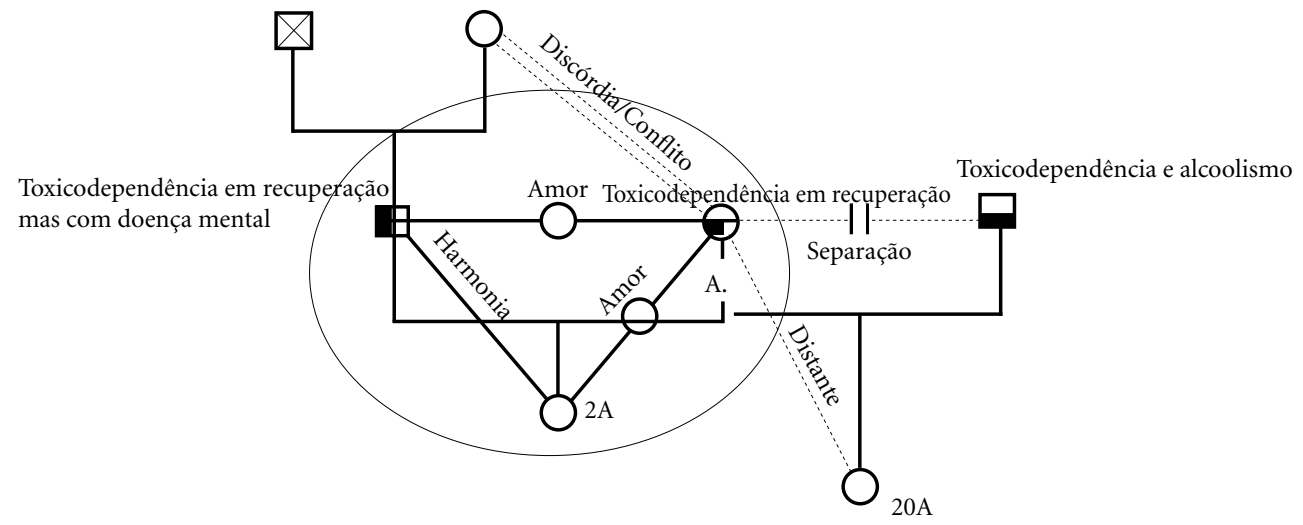

Figura 1. Genograma Simples tendo por base a informação fornecida pela participante Ana (nome fictício).

mitindo ao investigador procurar centrar-se no fenómeno em estudo, deixando de lado aspetos muito abstratos ou divagações relacionadas com outros assuntos, permitindo-nos recolher e destapar os fenómenos ${ }^{14}$.

Entrando especificamente na análise fenomenológica, a investigadora mergulhou nos dados, fazendo leituras e releituras circulares sobre os mesmos ${ }^{13}$, buscando a compreensão de cada dado em relação ao todo, e do todo em relação a cada dado (círculo hermenêutico). Recorremos seguidamente ao movimento circular de leituras e releituras, aos pressupostos processuais de Van Manen ${ }^{14}$, procurando a investigadora voltar-se para a natureza da experiência vivida, dedicando-se e concentrando-se no fenómeno do seu interesse e acedendo às "estruturas da experiência"14, no ato de construir os temas fenomenológicos com base na experiência vivida e narrada.

Constituindo-se a fenomenologia o método para chegar às estruturas do significado das experiências vividas, o mesmo, também denominado de redução, consiste em dois movimentos opostos que se complementam um ao outro ${ }^{14}$. Num movimento, procurar-se-á colocar entre parêntesis (Epoché ou Bracketing) as ideias preexistentes ou preconcebidas do investigador face ao fenómeno. Num outro movimento, em sentido contrário, procurar-se-á a essência do fenómeno em estudo através da redução (Reduction), em que se pretenderá uma descrição rica da experiência face ao fenómeno em estudo e a sua tradução "através de clusters, insights ou conjunto de temas a partir da compreensão dos relatos”14,15.

\section{Resultados e discussão}

Utilizando a metáfora de estar à tona da água, estas mulheres procuraram na gravidez a possibilidade da transcendência e de mudança. De forma não planeada e não desejada, a gravidez surge na vida destas mulheres gerando sentimentos de ambivalência, mas com expressão de uma forte ligação e vinculação ao seu bebé (Quadro 2). A comunicação e a relação estabelecida entre a mãe e o futuro bebé ocorre gradualmente ao longo dos meses de gravidez e é, sem dúvida, responsável pelo desenvolvimento da vinculação entre a díade mãe/filho ${ }^{16}$.

É no momento do trabalho de parto e parto que estas mulheres expressam o sentirem a diferença no cuidar, o medo, mas também a felicidade e o amor pelos seus bebés (Quadro 3). Os profissionais de saúde deverão ser promotores do combate ao estigma, que tanto parece condicionar a vida destas e de outras mulheres, levando à perda de oportunidades, prejuízo da autoestima e autoconceito, qualidade de vida, suporte social e empoderamento ${ }^{17}$. Segundo Banwell e Bammer $^{18}$, as mulheres que usam drogas ilícitas são muitas vezes culpadas por dificuldades no exercício da parentalidade, ao contrário dos outros grupos de mulheres, o que se traduz em estigma face a estas mulheres, representando um obstáculo à concretização dos seus projetos pessoais. 
No período pós-parto e primeiro mês de vida dos seus filhos, estas mulheres exprimem o sentirem-se mães e a capacidade de cuidarem dos seus filhos, em que as exigências encetadas no mesmo, e a possibilidade de institucionalização do filho, a vigilância por parte de outros e o estigma social em relação à capacidade em serem mães, as fazem exprimirem-se com tristeza e revolta (Quadro 4). O estudo inglês que procurou compreender de que forma programas de reabilitação para a toxicodependência podem criar oportunidades de afirmação da identidade materna, mostra-nos que as mulheres toxicodependentes em processo de reabilitação encontram-se motivadas em agir no supremo interesse do seu descendente, tendo uma oportunidade para se reabilitar do uso de drogas $^{19}$.

Retornando ao primeiro ano de vida de seus filhos, estas mulheres culpabilizam-se por uma história de vida passada. Se a perceção do estigma social em relação à capacidade em serem mães é enfatizado por estas mulheres, é com o sentimento de orgulho e de vínculo ao seu filho, que estas se sentem mães e com capacidade para cuidarem dos seus filhos, evocando aqueles que foram capazes de cuidarem delas (Quadro 5).

Quadro 2. A gravidez - o situar-se na díade mãe-filho.

\begin{tabular}{|l|l|l|l|}
\hline $\begin{array}{l}\text { Experiência vivida } \\
\text { da transição para } \\
\text { o papel maternal }\end{array}$ & \multicolumn{1}{|c|}{ Tema } & $\begin{array}{l}\text { O Situar-se na Díade } \\
\text { Mãe-Filho }\end{array}$ & \multicolumn{1}{c|}{ Exemplo de Extrato das Narrativas } \\
\cline { 2 - 4 } $\begin{array}{l}\text { de mulheres } \\
\text { com problemas } \\
\text { de adição a } \\
\text { substâncias } \\
\text { psicoativas no } \\
\text { momento da } \\
\text { gravidez }\end{array}$ & $\begin{array}{l}\text { Variaçes } \\
\text { no Tema }\end{array}$ & $\begin{array}{l}\text { - A Ligação/ } \\
\text { Vinculação ao Bebé } \\
\text { - O Sentir Medo } \\
\text { de Alterações/ } \\
\text { Malformações no Bebe } \\
\text { - O Sentir Medo de }\end{array}$ & $\begin{array}{l}\text { [...] mas depois conforme ela ia crescendo dentro } \\
\text { de mim foi, eh pá, foi uma paz...uma coisa } \\
\text { maravilhosa....ai! [...] Gostava de dormir agarrada } \\
\text { à minha barriga quando ela já estava grande e } \\
\text { sentir a bebé a mexer, é uma coisa maravilhosa, } \\
\text { doutora. [...] Eu falava para a minha filha, } \\
\text { desabafava com ela, ela estava ali comigo, dentro de } \\
\text { mim.” (Dora - N1). }\end{array}$ \\
\hline
\end{tabular}

Quadro 3. O Parto - O Situar-se na Díade Mãe-Filho.

\begin{tabular}{|c|c|c|c|}
\hline Experiência vivida da & Tema & O Situar-se na Díade Mãe-Filho & Exemplo de Extrato das Narrativas \\
\hline $\begin{array}{l}\text { transição para o papel } \\
\text { maternal de mulheres } \\
\text { com problemas de } \\
\text { adição a substâncias } \\
\text { psicoativas no } \\
\text { momento do trabalho } \\
\text { de parto e parto }\end{array}$ & $\begin{array}{l}\text { Variações no } \\
\text { Tema }\end{array}$ & $\begin{array}{l}\text { - A Ligação/Vinculação ao Bebé } \\
\text { - O Sentir Medo de Alterações/ } \\
\text { Malformações no Bebe } \\
\text { - O Sentir Medo de Perder o } \\
\text { Filho }\end{array}$ & $\begin{array}{l}\text { "[...] estava farta de dores, mas } \\
\text { também ao mesmo tempo, fogo, } \\
\text { estava feliz, queria ver a minha filha, } \\
\text { abraçá-la, queria ver a minha filha, } \\
\text { a gravidez durou séculos." (Dora - } \\
\text { N1). }\end{array}$ \\
\hline
\end{tabular}

Quadro 4. O Pós-Parto - O Situar-se no Projeto da Maternidade.

\begin{tabular}{|c|c|c|c|}
\hline \multirow[b]{2}{*}{$\begin{array}{l}\text { Experiência vivida } \\
\text { da transição para } \\
\text { o papel maternal } \\
\text { de mulheres } \\
\text { com problemas } \\
\text { de adição a } \\
\text { substâncias } \\
\text { psicoativas no } \\
\text { momento pós- } \\
\text { parto (até aos } \\
30 \text { dias após o } \\
\text { nascimento da } \\
\text { criança) }\end{array}$} & Tema & $\begin{array}{l}\text { O Situar-se no Projeto } \\
\text { da Maternidade }\end{array}$ & Exemplo de Extrato das Narrativas \\
\hline & $\begin{array}{l}\text { Variações } \\
\text { no Tema }\end{array}$ & $\begin{array}{l}\text { - O Sentir Estigma Social } \\
\text { em relação à Capacidade } \\
\text { em Ser Mãe } \\
\text { - O Sentir-se Igual a } \\
\text { outras Mães } \\
\text { - A Revolta em Relação } \\
\text { às Instituições e Técnicos } \\
\text { de Segurança Social }\end{array}$ & $\begin{array}{l}\text { "Quando a bebé estava lá eu é que fazia tudo, nos } \\
\text { primeiros dias eles é que queriam fazer e eu disse } \\
\text { eu quero a minha filha, eu quero fazer. [...] Uma } \\
\text { enfermeira lá no hospital então disse-me, anda cá, } \\
\text { anda cá, estica o braço vá, tens de aprender, não } \\
\text { pode ser só a ver. Eu fiquei tão contente, eu é que } \\
\text { lhe dava banho, trocava as fraldas, dava de comer, } \\
\text { tudo, tudo, eles não faziam quase nada, tratavam } \\
\text { dos outros. Isto era muito importante para mim, } \\
\text { eu aprendi a fazer e a minha filha sentia que era } \\
\text { eu." (Dora - N1). }\end{array}$ \\
\hline
\end{tabular}


Quadro 5. O primeiro ano de vida - o situar-se na díade mãe-filho.

\begin{tabular}{|l|l|l|l|}
\hline $\begin{array}{l}\text { Experiência vivida da } \\
\text { transição para o papel } \\
\text { maternal de mulheres } \\
\text { com problemas de } \\
\text { adição a substâncias } \\
\text { psicoativas após o } \\
\text { primeiro ano de vida } \\
\text { do filho }\end{array}$ & Tema & $\begin{array}{c}\text { O Situar-se no Projeto da } \\
\text { Maternidade }\end{array}$ & \multicolumn{1}{|c|}{ Exemplo de Extrato das Narrativas } \\
\cline { 2 - 4 } & Tema & $\begin{array}{l}\text { - O Sentir Estigma Social } \\
\text { em relação à Capacidade em } \\
\text { Ser Mãe }\end{array}$ & $\begin{array}{l}\text { Uma coisa que me marcou, foi que } \\
\text { quando eu tive o meu filho eu era a } \\
\text { toxicodependente e a outra senhora } \\
\text { que estava lá também a ter o bebé, não } \\
\text { era. [...]! É como lhe digo, fazem muita } \\
\text { distinção! (Aurora - N14). }\end{array}$ \\
\hline
\end{tabular}

Através desta pesquisa, os enfermeiros poderão aceder à experiência vivida destas mulheres, e com ele refletirem sobre a necessidade inequívoca da prestação de cuidados de enfermagem significativos ao outro. Por outro, abordamos o método fenomenológico como método basilar no desenvolvimento da exploração e clarificação conceptual da ciência de enfermagem, tal como fez a autora Swanson ${ }^{20}$ através de três investigações fenomenológicas no âmbito da saúde materna, construindo uma teoria de médio alcance, que a levou à definição do cuidar em enfermagem como "[...] a forma de relacionar crescendo com um outro significativo, por quem nos sentimos pessoalmente envolvidos e responsáveis".

De acordo com Swanson ${ }^{20,21}$, uma das pedras basilares do cuidar em enfermagem é a manutenção da crença na pessoa e na sua capacidade de superar eventos e transições. Por outro, tal como este estudo se propôs, conhecer, significa compreender os acontecimentos e o significado dos mesmos na vida da pessoa.

$\mathrm{O}$ enfermeiro também tem de estar com, isto é, estar emocionalmente presente, em que presença emocional é uma forma de partilha de significados, sentimentos e da experiência vivida pela pessoa. O enfermeiro é aquele que faz, e que faz com sentido em que Fazer inclui confortar a pessoa; antecipar as suas necessidades; desempenhar funções com habilidade e competência; proteger a pessoa e preservar a sua dignidade ${ }^{20}$. Por último, o enfermeiro é o profissional que possibilita e capacita em que possibilitar/capacitar é facilitar a passagem da pessoa nos acontecimentos e transições de vida (Figura 2).

\section{Considerações finais}

A transição para o Papel Maternal de Mulheres com Problemas de Adição a Substâncias Psico- ativas, da gravidez ao primeiro ano de vida do filho é desvelada quando estas mulheres narram e se situam num momento passado de história de consumos, quando se sentiram investidas e cuidadas pelos profissionais de saúde; quando se situam num passado difícil em que as relações familiares, muitas vezes, são fugazes e pouco estruturadas; quando se sentiram desinvestidas e não cuidadas pelos outros; mas fundamentalmente quando se situaram numa relação vinculativa e afetiva Mãe-Filho, valorizando os momentos do tempo presente e permitindo-se sonhar e projetar um futuro melhor.

Pelos achados obtidos, verificamos que o fenómeno em estudo é de elevada complexidade. Desvelando-se uma imagem estereotipada, estas mulheres salientam a necessidade de uma maior visibilidade para a equipa de saúde e a desocultação das suas experiências enquanto mães. $\mathrm{Na}$ possibilidade da consecução do papel maternal, estas mulheres gravitam de forma transicional para a identidade em serem mães, culpabilizando-se por uma história de vida passada e todas as consequências que esta determinou em suas vidas e de seus filhos, sentindo por isso, necessidade de cortar com um passado ainda muito presente. Se a perceção do estigma social em relação à capacidade em serem mães é enfatizado por estas mulheres, é com o sentimento de orgulho e de vínculo ao seu filho, que estas se sentem mães e com capacidade, em alguns casos, para cuidarem dos seus filhos.

Pela necessidade de ajustamento ao fenómeno da maternidade, de adaptação e na experiência simultânea de uma transição desenvolvimental, situacional e de saúde-doença, a consecução maternal faz-se, para estas mulheres, num passado e numa história de consumos, em que o projeto de maternidade é presente, fortemente alicerçado na díade mãe-filho. 


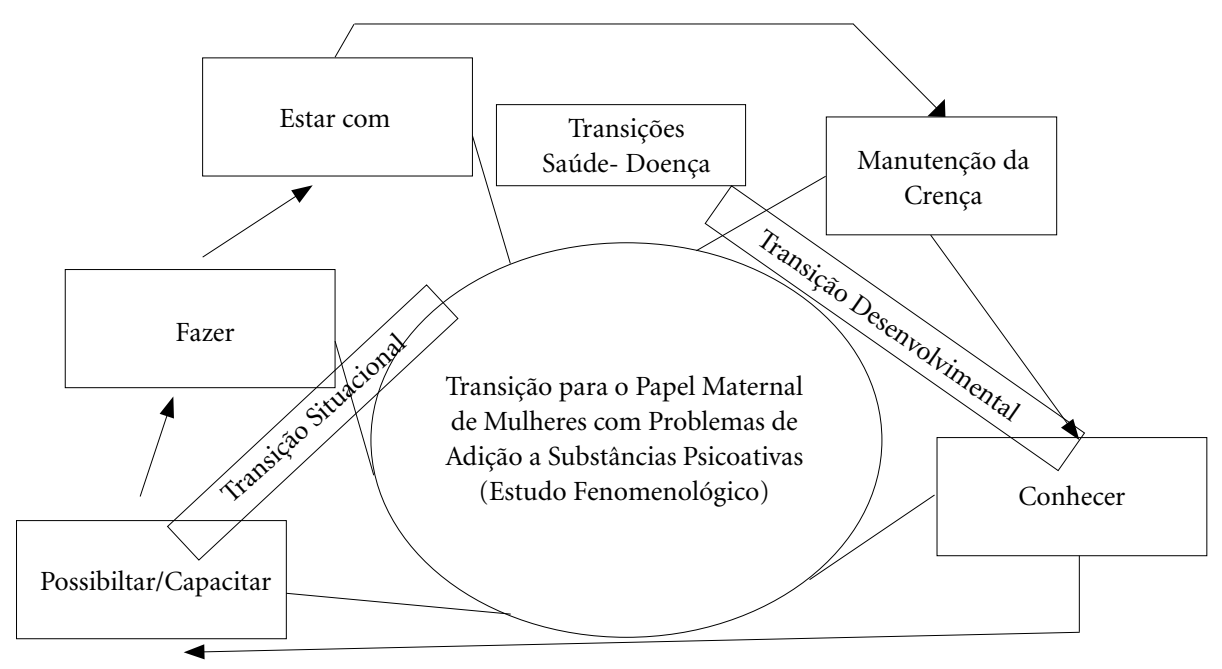

Figura 2. Fenómeno do Estudo alicerçado na Teoria de Meleis ${ }^{7}$ e de Swanson ${ }^{20,21}$.

\section{Colaboradores}

CMG Henriques e HCP Catarino - Conceptualização, Pesquisa, visualização e redação do artigo. MAR Botelho - Conceptualização, Investigação, visualização e redação do artigo. 


\section{Referências}

1. Paterson J, Zderad L. Humanistic Nursing. Copyright Status: The Project Gutenberg eBook; 2008. [cited 2018 Apr 12] Available at: http://www.gutenberg.org/ ebooks $/ 25020$

2. Loureiro LMJ. Adequação e Rigor na Investigação Fenomenológica em Enfermagem - Crítica, Estratégias e Possibilidades. Referência 2006; 2(Jun):21-32.

3. Heidegger M. Ser e Tempo. Petrópolis: Editora Vozes; 2014.

4. Dilthey W. Introduction to the Human Sciences. An Attempt to Lay a Foundation for the Study of Society and History. Detroit: Wayne State University Press; 1989.

5. Heidegger M. A Origem da Obra de Arte. Lisboa: Edições 70; 2008.

6. Weaver K, Olson J. Understanding paradigms used for nursing research. J Adv Nurs 2006; 53(4):459-469.

7. Meleis A. Theoretical Nursing: Development and Progress. Philadelphia: Williams \& Wilkins; 2012.

8. Lopes J. Ser Cuidado por Um Enfermeiro Gestor de Caso. A Experiência Vivida da Pessoa com Problemas de Adição [tese]. Lisboa: Universidade de Lisboa; 2012.

9. Henriques C, Botelho M, Catarino H. Tornar Refletido o Pré-Refletido: O Contributo da Fenomenologia para a Disciplina de Enfermagem. Investigação Qualitativa em Saúde. CIAIQ: Atas do $7^{\circ}$ Congresso Ibero-Americano em Investigação Qualitativa, 2018; 1497-1506.

10. Gadamer HG. Truth and Method. 56 ed. London: Continuum Publishing Group; 2006

11. Gadamer HG. Verdade e método I: traços fundamentais de mais uma hermenêutica filosófica. Petrópolis: Vozes; 2015.

12. Gadamer HG. Verdade e Método II. Complementos e Índice. Petrópolis: Vozes; 2011.

13. Smith JA, Flowers P, Larkin M. Interpretative Phenomenological Analysis: Theory, Method and Research. London: Sage Publications Ltd; 2013.

14. Van Manen M. Phenomenology of Practice. MeaningGiving Methods in Phenomenological Research and Writing. Walnut Creek: Left Coast Press Inc.; 2014.
15. Moreira DA. O método fenomenológico na pesquisa. São Paulo: Thompson Pioneira; 2004.

16. Moura-Ramos M, Canavarro MC. Adaptação parental ao nascimento de um filho: Comparação da reactividade emocional e psicossintomatologia entre pais e mães nos primeiros dias após o parto e oito meses após o parto. Análise Psicológica 2007; 3(XXV):399413.

17. Xavier S, Klut C, Neto A, Ponte G, Melo J. Mental Health Stigma: Where do We Stand? Psicologos 2013; Vol.11(2):10-21.

18. Banwell C, Bammer G. Maternal habits: Narratives of mothering, social position and drug use. International Journal of Drug Policy 2006; 17(6):504-513.

19. Radcliffe P. Motherhood, pregnancy, and the negotiation of identity: The moral career of drug treatment. Soc Sci Med 2011; 72(6):984-991.

20. Swanson KM. Nursing as Informed Caring for the Well-Being of Others. J Nurs Sch 1993; 25(4):352-357.

21. Swanson KM. Empirical Development of a Middle Range Theory of Caring. Nurs Res 1991; 40(3):161166.

Artigo apresentado em 28/03/2020

Aprovado em 02/05/2020

Versão final apresentada em 04/05/2020

Editores chefes: Maria Cecília de Souza Minayo, Romeu Gomes, Antônio Augusto Moura da Silva 
